\title{
Electron Microscopic Study on the Cellular Interrela- tionships in the Smooth Muscle
}

\author{
Junichiro Nagasawa and Taizo Suzuki \\ Department of Applied Physiology (Prof. T. Suzuki), \\ Tohoku University School of Medicine, Sendai
}

\begin{abstract}
In the smooth muscle cells of the rabbit colon and of the guinea pig urinary bladder, pinocytotic vesicles were frequently observed occurring on both sides of two opposing smooth muscle cell membranes. The authors named this specialized structure paired pinocytosis. The regular appearance of this paired pinocytosis with zonula adherens (intermediate junction) or with macula adherens (desmosome) along the contact surface of the smooth muscle cells was characteristically found in these tissues. The arrangements of the intermediate junctions or the desmosomes in these tissues sometimes structurally resemble the intercalated disc of the heart muscle. The possible significance of this structure is discussed in relation to the problems of the intercellular conduction of excitation in the smooth muscle tissue.
\end{abstract}

One of the important problems in the physiology of the smooth muscle is the mode of the transmission of excitation between smooth muscle cells, and many electron microscopic observations have been carried out in connection with this problem.

Protoplasmic continuity between smooth muscle cells was reported by Mark ${ }^{1}$ in the rat uterus and by Thaemert ${ }^{2}$ in the rat intestinal smooth muscle, but its constancy is rather questionable in the results with the modern techniques in electron microscopy. Intercellular bridges were observed and reported by Bergman, ${ }^{3}$ but it does not frequently occur in smooth muscle tissues except in the rat ureter.

The intercellular membrane structure nexus reported by Dewey and Barr ${ }^{4,5}$ and Oosaki and Ishii $^{6}$ in the intestinal smooth muscles is essentially of a structure similar to the zonula occludens (tight junction) reported by Farquhar and Palade $^{7}$ in various epithelia. It seems to be one of the characteristic attachment apparatuses of the smooth muscle cells, though its appearance seems to be inconstant and limited only to the saline pre-incubated and permanganate fixed materials.

The authors observed abundant intermediate junctions and desmosomes together with pinocytotic vesicles in the smooth muscle cells of the rabbit colon

Received for publication, December 16, 1966.

This work was supported by a grant from the Population Council (U.S.A.). 
and of the guinea pig urinary bladder fixed with osmium tetroxide without pre-incubation.

The regular alternation of the paired pinocytosis with desmosomes or with intermediate junctions is one of the characteristic findings in these tissues and seems to play an important role in the excitation conduction between smooth muscle cells.

Pinocytotic vesicles at the tapering ends of two adjacent smooth muscle cells and the intrusion of a process of one muscle cell into the other, which are also characteristically found in these tissues, will be described.

\section{Materials and Methods}

The present observation was carried out on the smooth muscle cells from the rabbit colon and from the guinea pig urinary bladder. For comparison of the cellular interrelationships, smooth muscles of the vas deferens and ureter of guinea pigs were also submitted to observation.

The preparations were quickly cut out and gently stretched to its in situ length on a paraffin sheet. After 10 minutes' pre-fixation by dripping ice cold fixatives on the specimens, they were cut to small blocks and further fixed with fresh fixatives for about 2 hours in a refrigerator.

The fixatives used were $1.2 \%$ potassium permanganate, $1 \%$ osmium tetroxide or the equivalent volume mixture of potassium permanganate and osmium tetroxide solutions. They were mixed either with veronal acetate buffer, ${ }^{8}$ with Dalton's dichromate buffer ${ }^{9}$ or with Millonig's phosphate buffer ${ }^{10}$ and brought to $\mathrm{pH}$ 7.4. Of these the veronal acetate buffer gave the most satisfactory results.

Dehydration was performed by passing the specimens through the ascending series of ethanol. The specimens were embedded in Epon 812 according to the method of Luft." Thin sections were cut with glass knives on a Porter-Blum MT-2 microtome, double stained with $2.5 \%$ uranyl-acetate and lead citrate, and examined with a Hitachi HS-7 electron microscope.

\section{Orservations}

All the smooth muscle cells observed had a complete envelope of the cell membrane and no intercellular protoplasmic continuity between muscle cells was observed. A thin sheet of external lamina enclosed the entire surface of the cells, except in specialized regions where intrusions of muscle cell processes did occur.

The contours of the smooth muscle cells were dependent upon the degree of muscle contraction at the time of fixation as already described by Rhodin ${ }^{12}$ and Lane. ${ }^{13}$ The highly irregular interdigitations of muscle cell processes were frequently observed in the preparations which were fixed intentionally in the state of free contraction. 
Numerous interdigitations were observed in the preparation of the rat ureter. Sometimes a contact of cellular processes was observed which was similar to the intercellular bridge described by Bergman. ${ }^{3}$ But, in general, the surface of smooth muscle cells was almost smooth and parallel with each other when the muscle cells were fixed in a properly extended condition (Fig. 1).

\section{Pinocytotic vesicles and junctional complex in smooth muscle}

The smooth muscle cells have been known to contain numerous pinocytotic vesicles beneath the entire surface of the cell membrane. But their occurrence varied from one smooth muscle cell to another. In general, they were not so abundant compared with the pinocytotic vesicles of the endothelial cells of the blood capillaries and certain types of epithelial cells. ${ }^{14}$

In the present observation, abundant pinocytotic vesicles were observed both in the smooth muscles of the rabbit colon (Figs. 2 to 5) and of the urinary bladder of the guinea pig (Figs. 7 and 12). Limited portions of the smooth muscle of the guinea pig vas deferens sometimes showed also rich pinocytotic vesicles (Figs. 8 and 15 ).

An impressive finding in the present study was the concurrent appearance of the pinocytotic vesicles on both sides of two opposing muscle cell membranes as illustrated in Figs. 2, 5, 9 and 12. The authors named this special structure paired pinocytosis. Several mitochondria were often observed to aggregate in the vicinity of the regions of the pinocytotic activity, suggesting that the cellular metabolism is very active at these places (Figs. 3, 4 and 7).

Farquhar and Palade ${ }^{7}$ defined the zonula adherens (intermediate junction) in the junctional complex of epithelia as follows. 'It is characterized by the close parallelism of the adjoining membrane over a certain distance, with conspicuous bands of dense material located in the subjacent cytoplasmic matrix and the presence of an intercellular space of about $200 \AA$ occupied by homogeneous amorphous material of low density.'

As shown in Figs. 3, 5, 9 and 10, the membrane apparatus found in the rabbit colon smooth muscle meets all the requirements of zonula adherens, though it appeared intermittently along the entire surface of the opposing cell membranes. In the urinary bladder smooth muscle, desmosomes with a discrete central line between intercellular space were sometimes found (Figs. 11 and 12), although intermediate junctions were more commonly found in this tissue (Fig. 7).

Intermediate junctions and desmosomes are abundantly present among the epithelial cells and the intercalated discs of the heart muscle, but in the smooth muscles, such regular appearance of the intermediate junctions or the desmosomes alternating with paired pinocytosis is quite unusual.

In other smooth muscles, pinocytotic vesicles and sometimes thickening of the muscle cell membrane have been reported, but usually they occur unilaterally 
and do not alternate with each other.

\section{Pinocytotic vesicles at the longitudinal ends of smooth muscle}

Fine structure of the site of the cellular contact at the tapering ends of the smooth muscle has not been clearly known. In the course of the present observation, unusually rich pinocytotic vesicles were found at the longitudinal ends of the smooth muscle cells of the rabbit colon (Figs. 13 and 14). It seems likely from these illustrations that at the longitudinal ends of the smooth muscles, the pinocytotic vesicles also play an important role in the interconnection of smooth muscle cells.

Fig. 15 shows another example of the aggregate of the pinocytotic vesicles along the contact surface of the smooth muscle cells of the vas deferens. The illustration suggests the possibility that paired pinocytosis could also occur in other smooth muscle preparations.

\section{Intrusion of muscle cell processes}

A specialized intercellular connection apparatus was often observed among a variety of smooth muscle tissues. It is the intrusion of a cytoplasmic process of one muscle cell into another. This intrusion was more frequently observed in the visceral smooth muscles such as gastrointestinal tract (especially in the pyloric smooth muscle of the rat) and ureter, where autonomic innervation is rather sparse and does not seem to be evenly distributed. ${ }^{15}$ Figs. 16 to 21 show the examples of the intrusions found in various smooth muscle tissues.

In general, the intruded cytoplasm stained homogeneously and contained no cellular organelles. But on rare occasions, as shown in Fig. 17, the intrusion contained myofibrils and small vesicles similar to pinocytotic vesicles. Sometimes remnant membraneous structures of mitochondria were seen (Figs. 19 and 20).

Intrusions were not evenly distributed in the section, and their occurrence seemed to be seriously influenced by the degree of extension of the muscle at the fixation. The more were intrusions observed, the more a muscle tissue was fixed in contracted state and the earlier the fixation was started. These results indicate that the intrusion is rather a labile structure, and in a living tissue more intrusions would be present than observed in electron microscopy.

The physiological significance of the intrusions or whether they play an important role in the intermuscular transmission of excitation or they merely serve as a mechanical support cannot be determined at present.

\section{Drscussion}

Farquhar and Palade ${ }^{7}$ separated the junctional complex of the epithelia into tripartite portions as zonula occludens (tight junction), zonula adherens (intermediate 
junction) and macula adherens (desmosome). Of these, the tight junction is characterized by the fusion of the opposing lateral cell membranes, and it has been widely found among various tissues. Nexus by Dewey and Barr ${ }^{5}$ indicates a special instance of the tight junctions occurring between smooth muscle cells.

In smooth muscles, nexus has been the most distinct morphological evidence that could substantiate the presence of pathways of low electrical resistance between the adjacent smooth muscle cells. But the nexus has not been constantly found among the variety of the mammalian smooth muscle tissues. ${ }^{16}$

According to Dewey and Barr, ${ }^{5}$ nexus can only be found in the preparations previously incubated in physiological saline and then fixed with potassium permanganate. Osmium tetroxide does not seem to be adequate for demonstrating the membrane fusion, though it occasionally brings about good results. ${ }^{6}$

A prolonged incubation in a saline inevitably causes swelling of cells and often tends to give serious damage to the fine structure. Hence the possibility could not be ruled out that nexus in the smooth muscles represented a secondary change associated with the swelling and adhesion of the muscle cells. In the present observation, where no pre-incubation in the saline was performed, the nexus structure could not be demonstrated. Instead, the alternation of the intermediate junctions or the desmosomes with paired pinocytosis was often observed.

There have been many papers which describe the presence of the membrane thickening or the dense region on the smooth muscle cell membrane, but a regular alternation of the intermediate junctions or the desmosomes with paired pinocytosis has not been reported in literature except in the mouse urinary bladder. ${ }^{17}$

The intercalated disc of the heart muscle is known to have all the three components of the junctional complex, and it is believed that this structure serves as pathways of low electrical resistance between heart muscle cells. The structural similarity of intercellular connection in the smooth museles of the colon and the urinary bladder to the intercalated disc of the heart muscle suggests that junctional complex also plays an important role in the conduction of excitation between smooth muscle cells, though in these smooth muscles paired pinocytosis is predominantly found in place of the tight junctions.

Kelly and Luft ${ }^{18}$ recently described that desmosomes and related attachment mechanisms of a variety of adhesion sites presented the evidence in support of the existence of a spectrum of attachment mechanisms in nature rather than of their distinct classes, and that embryonic attachment sites could display several levels of the spectrum in sequence as development proceeds.

According to this view, the difference in the occurrence of three components of the junctional complex among a variety of smooth muscle tissues will be interpreted as indicating a transient variance in the mechanical or the physio- 
logical states of individual smooth muscle cells and will not bear fundamental significances.

On the other hand, the pinocytotic vesicles in the smooth muscle seem to have two important roles other than their usual role in uptake of materials from the environment. The one is concerned with the decrease in the electrical resistance of the membrane and the other with the relaxing factors in the smooth muscle.

It is possible that specific membrane resistance is low at the site of pinocytotic activity because altered metabolism in adjacent parts modifies the character of the membrane and decreases its electrical resistance, which is indicated indirectly by the aggregate of mitochondria subjacent to the site of the pinocytotic activity as shown in Figs. 3 and 4.

The decreased electrical resistance at the limited site of the pinocytotic activity, especially when two such sites are located opposite each other and form a paired pinocytosis, is a mechanism advantageous in the excitation conduction between smooth muscle cells ${ }^{19}, 20$ like the instance of the nexus described by Dewey and Barr..$^{4,5}$

Concerning the relaxing factors, it is well known that smooth muscle cells contain but a small number of sarcoplasmic reticulum compared with the skeletal and heart muscles, though they are not completely devoid of this structure (Figs. 6, 14 and 15). Pinocytotic vesicles in the smooth muscle cells are the only comparable structure with the sarcoplasmic reticulum in the skeletal muscle.

Rostgaard and Barrnett ${ }^{21}$ observed that the pinocytotic vesicles in the rat intestinal smooth muscle showed an enzymatic activity in hydrolyzing nucleosides di- and triphosphates. It is well known that relaxing factors in the skeletal muscle need the energy of ATP to combine with calcium ions. Rostgaard and Barrentt's observation together with this fact strongly suggests that pinocytotic vesicles in the smooth muscle is the site that contains something like the relaxing factors in the skeletal muscle, and regulate the contraction and relaxation of the smooth muscle.

The present observation that paired pinocytosis regularly alternates with the intermediate junctions or the desmosomes in certain types of smooth muscles is another proof in favor of the excitation conduction between smooth muscle cells, though it is not known at present to what extent paired pinocytosis occurs in other smooth muscle tissues.

\section{References}

1) Mark, J.S.T. An electron microscope study of uterine smooth muscle. Anat. Rec., 1956, 125, 473-494.

2) Thaemert, J.C. Intercellular bridges as protoplasmic anastomoses between smooth muscle cells. J. biophysic. biochem. Cytol., 1959, 6, 67-70.

3) Bergman, R.A. Intercellular bridges in ureteral smooth muscle. Bull. Johns Hopkins Hosp., 1958, 102, 195-202. 
4) Dewey, M.M. \& Barr, L. Intercellular connection between smooth muscle cells : the nexus. Science, 1962, 137, 670-672.

5) Dewey, M.M. \& Barr, L. A study of the structure and distribution of the nexus. J. Cell Biol., 1964, 23, 553-585.

6) Oosaki, T. \& Ishii, S. Junctional structure of smooth muscle cells. J. Ultrastruct. Res., $1964,10,567-577$.

7) Farquhar, M.G. \& Palade, G.E. Junctional complexes in various epithelia. $J$. Cell Biol., 1963, 17, 375-412.

8) Palade, G.E. A study of fixation for electron microscopy. J. exp. Med., 1952, 95, 285-297.

9) Dalton, A.J. A chrome-osmium fixative for electron microscopy. Anat. Rec., 1955, 121, 281.

10) Millonig, G. Further observations on a phosphate buffer for osmium solutions in fixation. In: Electron Microscopy, edited by S.S. Breese, Jr., Academic Press, Inc., New York, 1962, P-8.

11) Luft, J.N. Improvements in epoxy resin embedding methods. J. biophysic. biochem. Cytol., 1961, 9, 409-414.

12) Rhodin, J.A.G. Fine structure of vascular walls in mammals with special reference to smooth muscle component. Physiol. Rev., 1962, 42, 49-81.

13) Lane, B.P. Alterations in the cytologic detail of intestinal smooth muscle cells in various stages of contraction. J. Cell Biol., 1965, 27, 199-213.

14) Fawcett, D.W. The Cell, Its Organelles and Inclusions. W.B. Saunders Company, Philadelphia and London, 1966, p. 389.

15) Nagasawa, J. \& Mito, S. Electron microscopic observations on the innervation of the smooth muscle. Tohoku J. exp. Med., 1967, 91, 277-293.

16) Merrillees, N.C.R., Burnstock, G. \& Holman, M.E. Correlation of fine structure and physiology of the innervation of smooth muscle in the guinea pig vas deferens. J. Cell Biol., 1963, 19, 529-550.

17) Caesar, R., Edwards, G.A. \& Ruska, H. Architecture and nerve supply of mammalian smooth muscle tissue. J. biophysic. biochem. Cytol., 1957, 3, 867-877.

18) Kelly, D.E. \& Luft, J.H. Fine structure, development, and classification of desmosomes and related attachment mechanisms. In: Electron Microscopy 1966, Vol. 2. edited by R. Uyeda, Maruzen Co., Ltd., Tokyo, 1966, pp. 401-402.

19) Prosser, C.L., Burnstock, G. \& Kahn, J. Conduction in smooth muscle: comparative structural properties. Amer. J. Physiol., 1960, 199, 545-552.

20) Lane, B.P. \& Rhodin, J.A.G. Cellular interrelationships and electrical activity in two types of smooth muscle. J. Ultrastruct. Res., 1964, 10, 470-488.

21) Rostgaard, J. \& Barmett, R.J. Fine structure localization of nucleoside phosphatases in relation to smooth muscle cells and unmyelinated nerves in the small intestine of the rat. $J$. Ultrastruct. Res., 1964, 11, 193-207. 


\section{Legends}

Fig. 1. Longitudinal section of the smooth muscle layer of the guinea pig taenia coli. Smooth muscle cells run parallel with one other and no cellular processes are observed. At the tapering ends of smooth muscle cells, aggregates of pinocytotic vesicles (P) are present. This specimen was fixed in a slightly extended condition. $\mathrm{OsO}_{4}$ fixation. $\times 5,000$.

Fig. 2. Longitudinal section of smooth muscle cells of the rabbit colon. Note that clusters of pinocytotic vesicles are often present on both sides of the opposing muscle cell membranes and form paired pinocytosis (P). Intermediate junctions (I) are predent adjacent to the pinocytotic vesicles. $\mathrm{OsO}_{4}-\mathrm{KMnO}_{4}$ fixation. $\times 5,800$.

Fig. 3., Paired pinocytosis (P) and intermediate junctions (I) of the opposing muscle cell membranes. Mitochondria lie subjacent to the pinocytotic vesicles. Rabbit colon, $\mathrm{OsO}_{4}-\mathrm{KMnO}_{4}$ fixation. $\times 15,000$.

Fig. 4! Paired pinocytosis (P) and unilateral aggregate of mitochondria beneath the membrane of the muscle cell on the right. Rabbit colon. $\times 10,000$.

Fig. 5. Paired pinocytosis (P) and intermediate junctions (I) alternatively occurring along the opposing smooth muscle cell membranes of the rabbit colon. $\times 17,500$.

Fig. 6. In $\mathrm{KMnO}_{4}$ fixed vas deferens, neither intermediate junction nor paired pinocytosis is present. Thin tubular smooth surfaced endoplasmic reticulum (ER) is seen at lower left and at upper right. Intrusion (In) of muscle cell process is seen at the center of the upper cell. Rat vas deferens, $\mathrm{KMnO}_{4}$ fixation. $\times \mathbf{1 5 , 0 0 0}$.

Fig. 7. Pinocytotic vesicles (P) occur deeply in the interdigitating cytoplasm of the muscle cell processes. Intermediate junctions (I) and aggregate of mitochondria are seen. Guinea pig urinary bladder, $\mathrm{OsO}-{ }_{4} \mathrm{KMnO}_{4}$ fixation. $\times 18,750$.

Fig. 8. Pinocytotic vesicles $(P)$ seen in the smooth muscle of vas deferens. Here they occur unilaterally and paired pinocytosis is not remarkable. Intrusion (In) of muscle cell process is seen at the center of the figure. Guinea pig vas deferens, $\mathrm{OsO}_{4}-$ $\mathrm{KMnO}_{4}$ fixation. $\times 22,500$.

Fig. 9. Intermediate junctions $(\mathrm{I})$ and paired pinocytosis $(\mathrm{P})$ regularly occur along the entire surface of the opposing smooth muscle cell membranes. Rabbit colon, $\mathrm{OsO}_{4}-\mathrm{KMnO}_{4}$ fixation. $\times 12,500$.

Fig. 10. In this figure successively occurring intermediate junctions(I) are clearly seen, but pinocytotic vesicles are not conspicuous. $\mathrm{Rabbit}$ colon, $\mathrm{O}_{8} \mathrm{O}_{4}-\mathrm{KMnO}_{4}$ fixation. $\times 17,500$.

Fig. 11. Desmosomes (D) and intermediate junctions (I) found in the smooth muscle cells of the gumea pig urinary bladder. External lamina of the musele cells is well preserved. A portion of a nucleus (N) of a smooth muscle cell is seen at the upper right. Guinea pig urinary bladder, $\mathrm{OsO}_{4}-\mathrm{KMnO}_{4}$ fixation. $\times 22,500$.

Fig. 12. Desmosomes (D) and intermediate junctions (I) occurring alternatively with paired pinocytosis $(\mathrm{P})$ in the guinea pig urinary bladder. Contrary to Fig. 12, well developed pinocytotic vesicles are present in this figure. Guinea pig urinary bladder, $\mathrm{OsO}_{4}-\mathrm{KMnO}_{4}$ fixation. $\times 25,000$.

Fig. 13. Abundant pinocytotic vesicles seen at the tapering end of the smooth muscle cell. This is an unusual occurrence, and the presence of pinocytotic vesicles (P) and collagen fibrils $(\mathrm{C})$ in the interior of the cell suggests that the section was cut almost tangential to the surface of the musole cell. Rabbit colon, $\mathrm{OsO}_{4}-\mathrm{KMnO}_{4}$ fixation. $\times 12,500$.

Fig. 14. An enlargement of a portion of Fig. 13. The wall of the pinocytotic vesicles has the unit membrane structure. Fine endoplasmic reticulum and RNP granules are distributed among the pinocytotic vesicles. $\times 60,000$.

Fig. 15. Pinocytotic vesicles present at the adjoining smooth muscle cell membranes of the guinea pig vas deferens. Junctional complex is not present. The interdigitated 
extracellular space $(\mathrm{Ex})$ is due to the free contraction at the fixation. Smooth surfaced endoplasmic reticulum $(\mathrm{ER})$ is seen at the upper left. Guinea pig vas deferens, $\mathrm{OsO}_{4}$ fixation. $\times 28,000$.

Fig. 16. Intrusion of a muscle cell process occurring in the taenia coli of the guinea pig. Unit membrane structure is well preserved, but no tight junction is observed even at the membrane of the intrusion. $\mathrm{KMnO}_{4}$ fixation. $\times 50,000$.

Fig. 17. Intrusion of muscle cell in the rabbit colon. Small vesicles are present at the neck of intrusion, and fine myofibrils are scattered irregularly in the intrusion body. Intermediate junctions (I) occur at both sides of the intrusion neck. Rabbit colon, $\mathrm{OsO}_{4}-\mathrm{KMnO}_{4}$ fixation. $\times 17,500$.

Fig. 18. Intrusion of muscle cell in the rat pylorus. Tight junction does not oceur even at the cell membrane of an intrusion site. Owing to permanganate fixation, cellular fine structures are not clearly recognized. Rat pylorus, $\mathrm{KMnO}_{4}$ fixation. $\times 25,000$.

Fig. 19. Two intrusions occurring in a smooth muscle cell of rat vas deferens. External lamina fill the narrow space between the opposing cell membranes of the intrusion site. Rat vas deferens, $\mathrm{KMnO}_{4}$ fixation. $\times 10,000$.

Fig. 20. Intrusion of smooth muscle cell in the guinea pig vas deferens. In this preparation, the space between the opposing cell membranes at the intrusion seems to be very narrow and leaves little room for the external lamina, but no tight junction is recognized under high power magnification of the figure. Membraneous structures, possibly remnants of mitochondria, are present in the intrusion body. Guinea pig vas deferens, $\mathrm{OsO}_{4}-\mathrm{KMnO}_{4}$ fixation. $\times 22,500$.

Fig. 21. Three intrusions occurring in the same smooth muscle cell of the ureter. Owing to the oblique direction of the section, the wall of the lower intrusion appears to be very thick. Guinea pig ureter, $\mathrm{OsO}_{4}-\mathrm{KMnO}_{4}$ fixation. $\times 20,000$. 


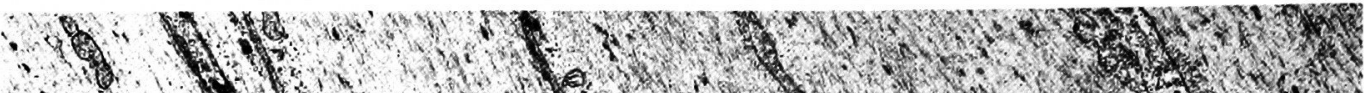

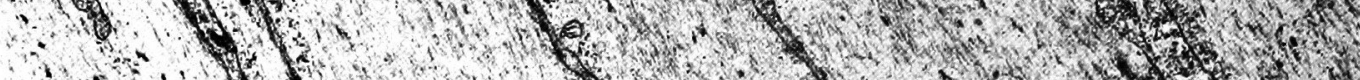

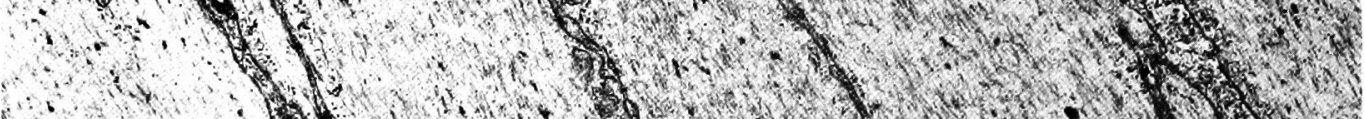

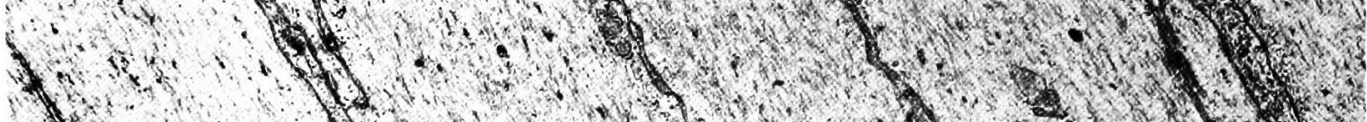

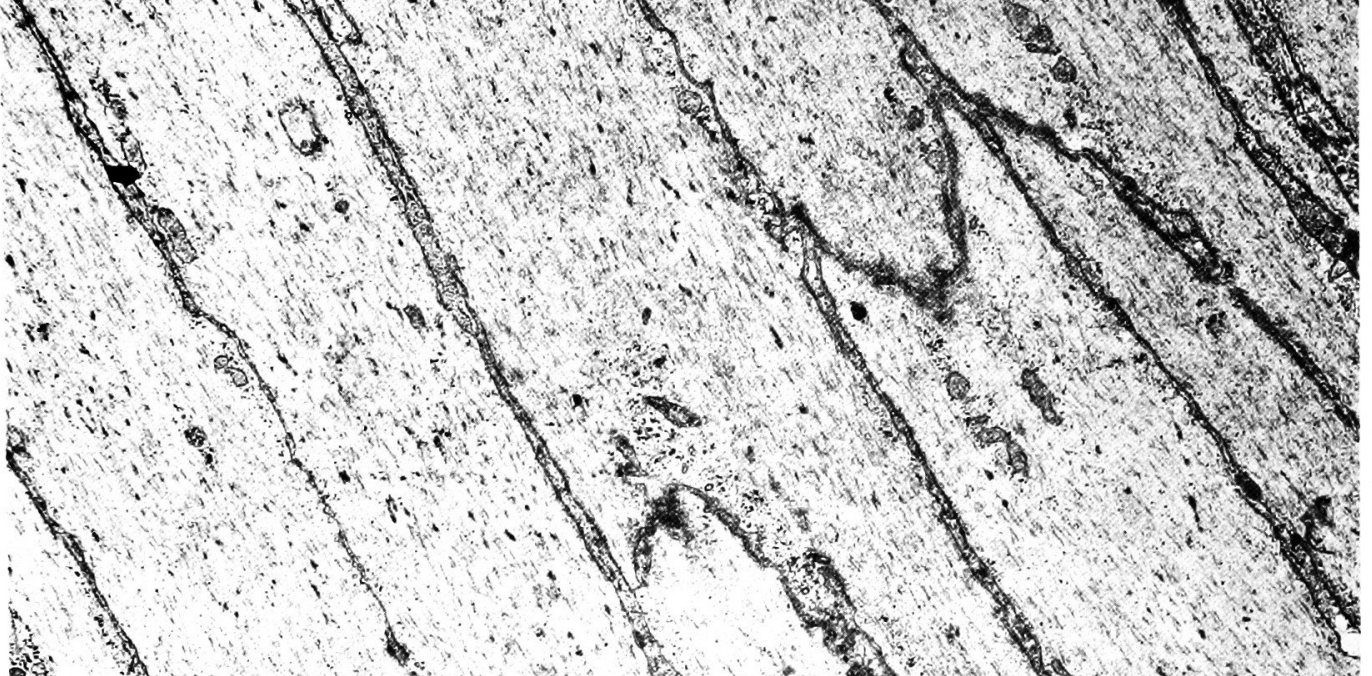
b.

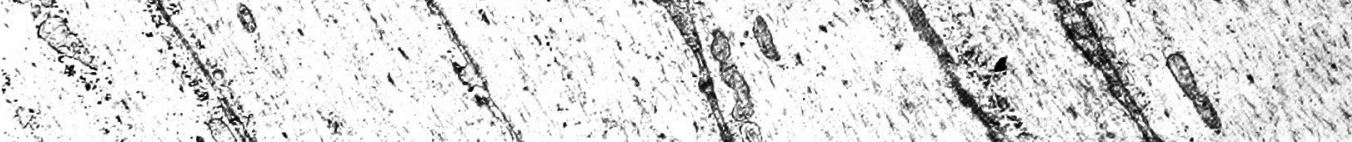
3.

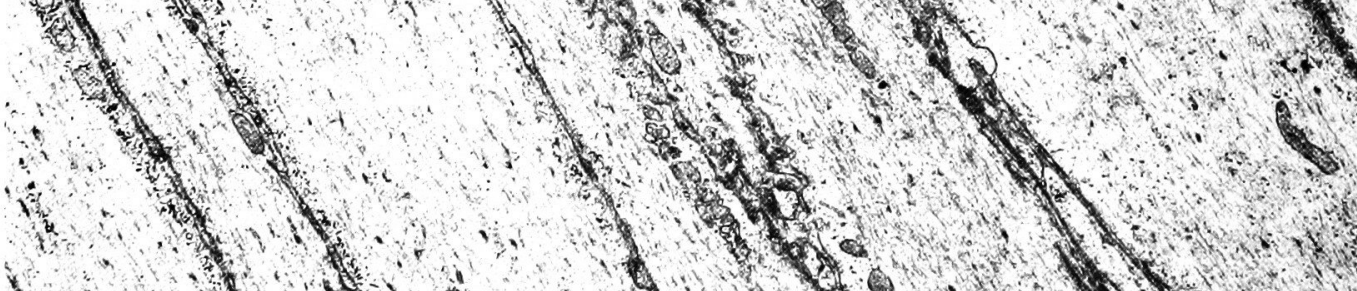

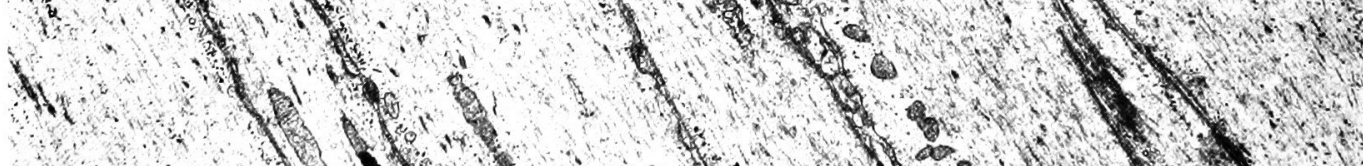

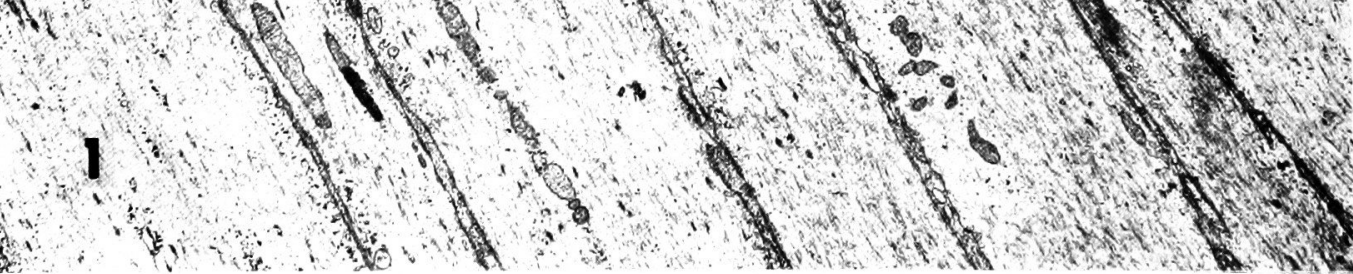




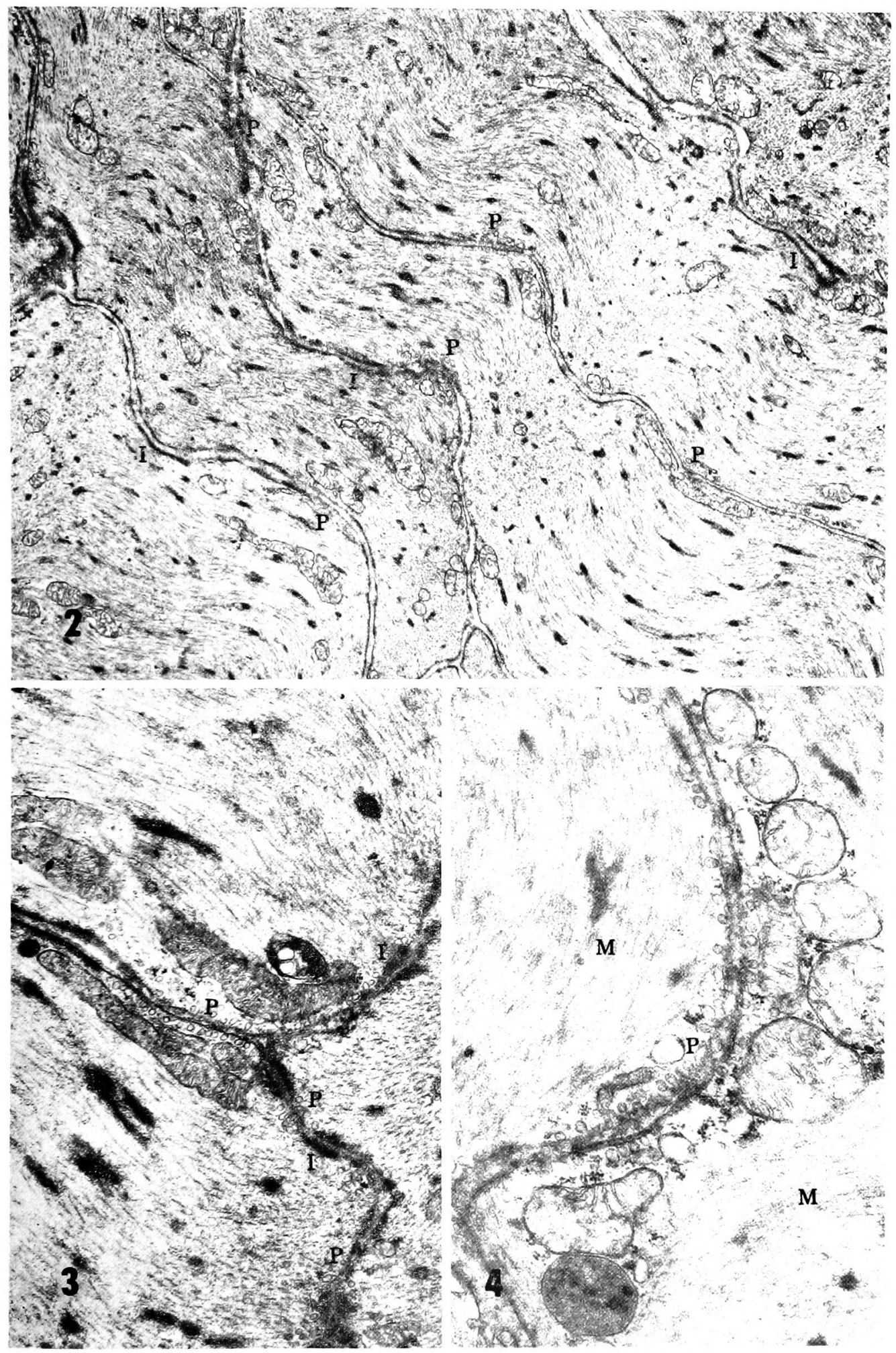




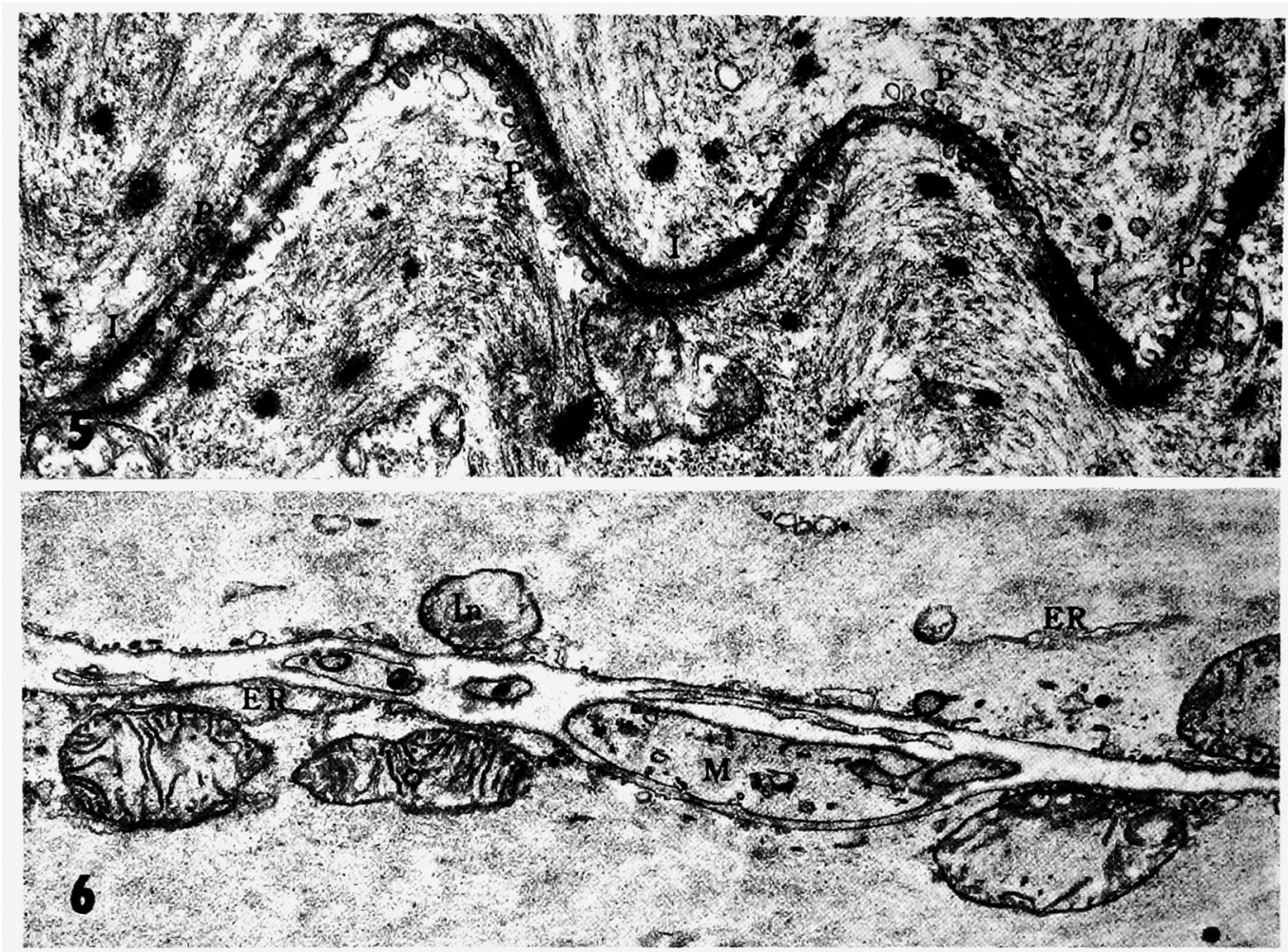

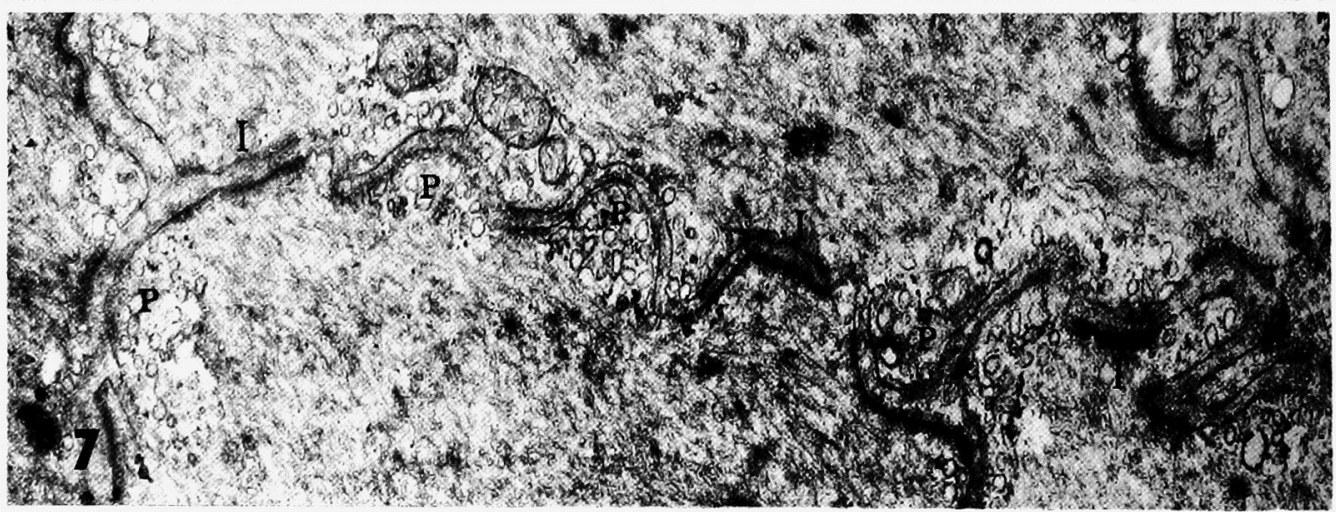

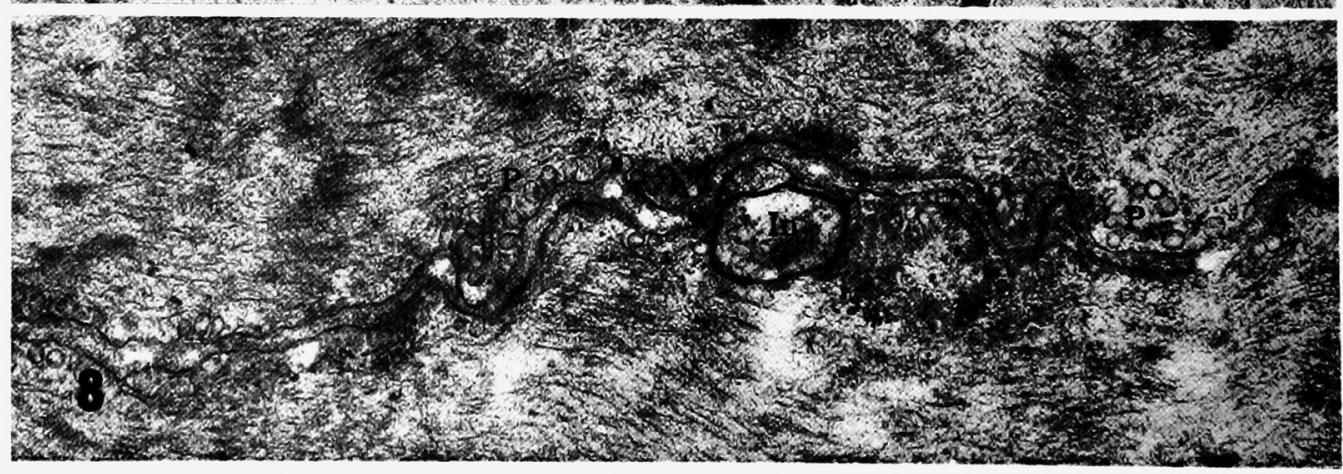




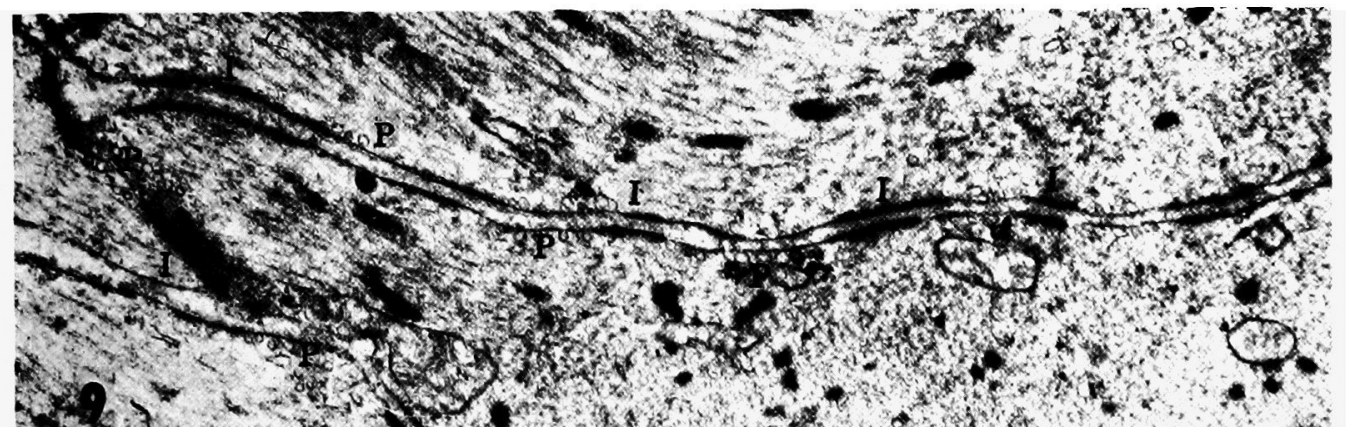

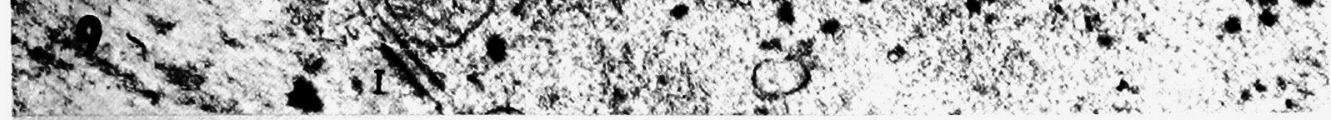

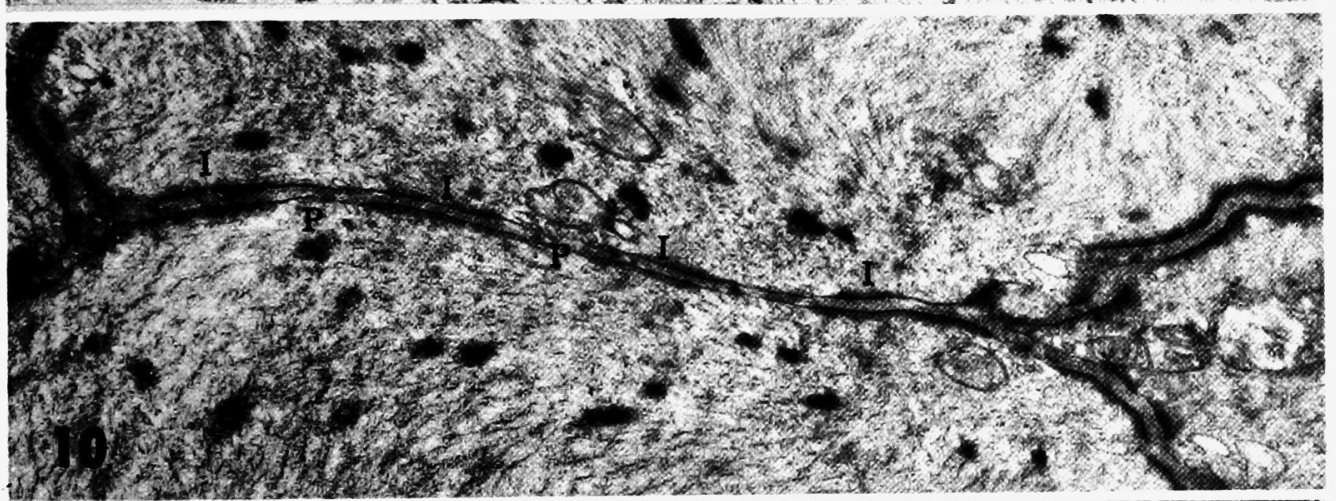

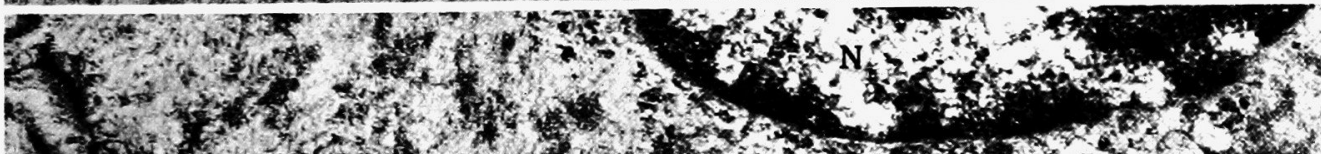

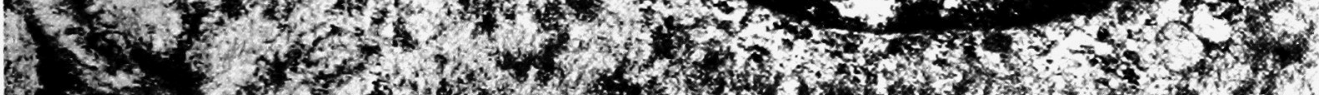

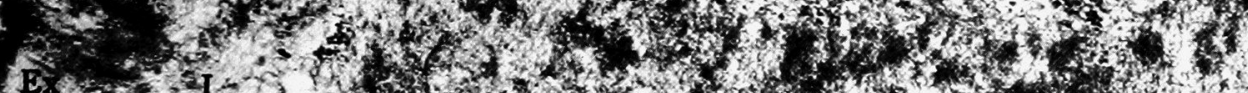

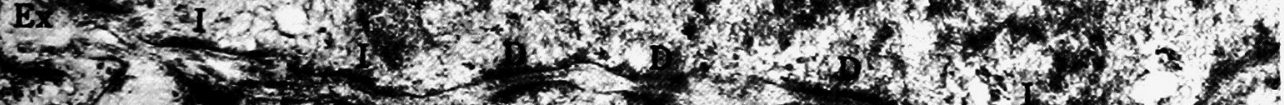
3.50
3

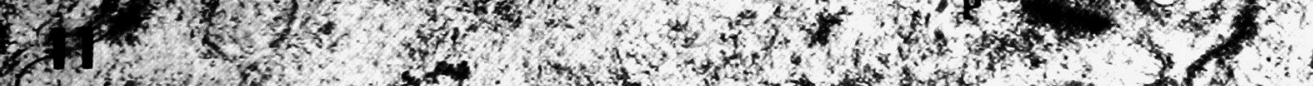

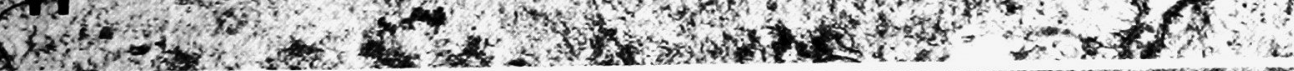
4.

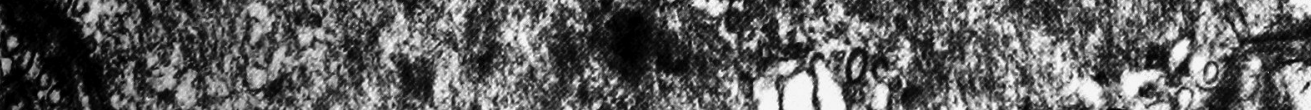

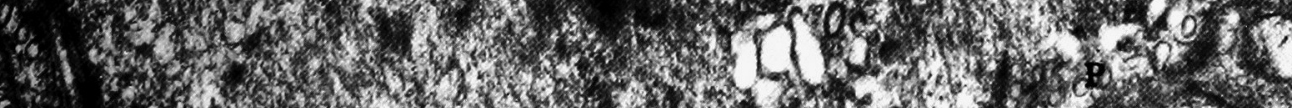
(6.7.

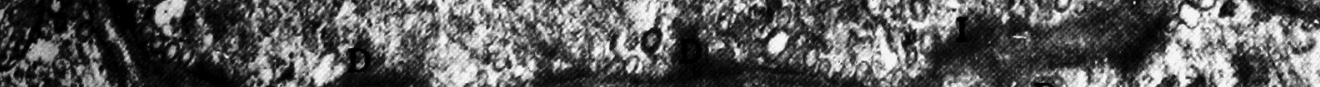

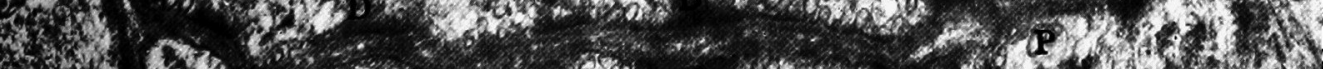

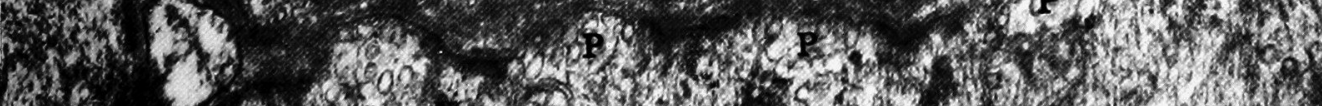

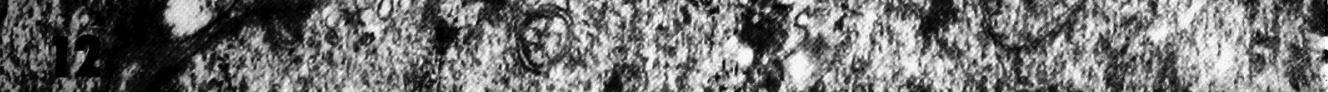
3. 


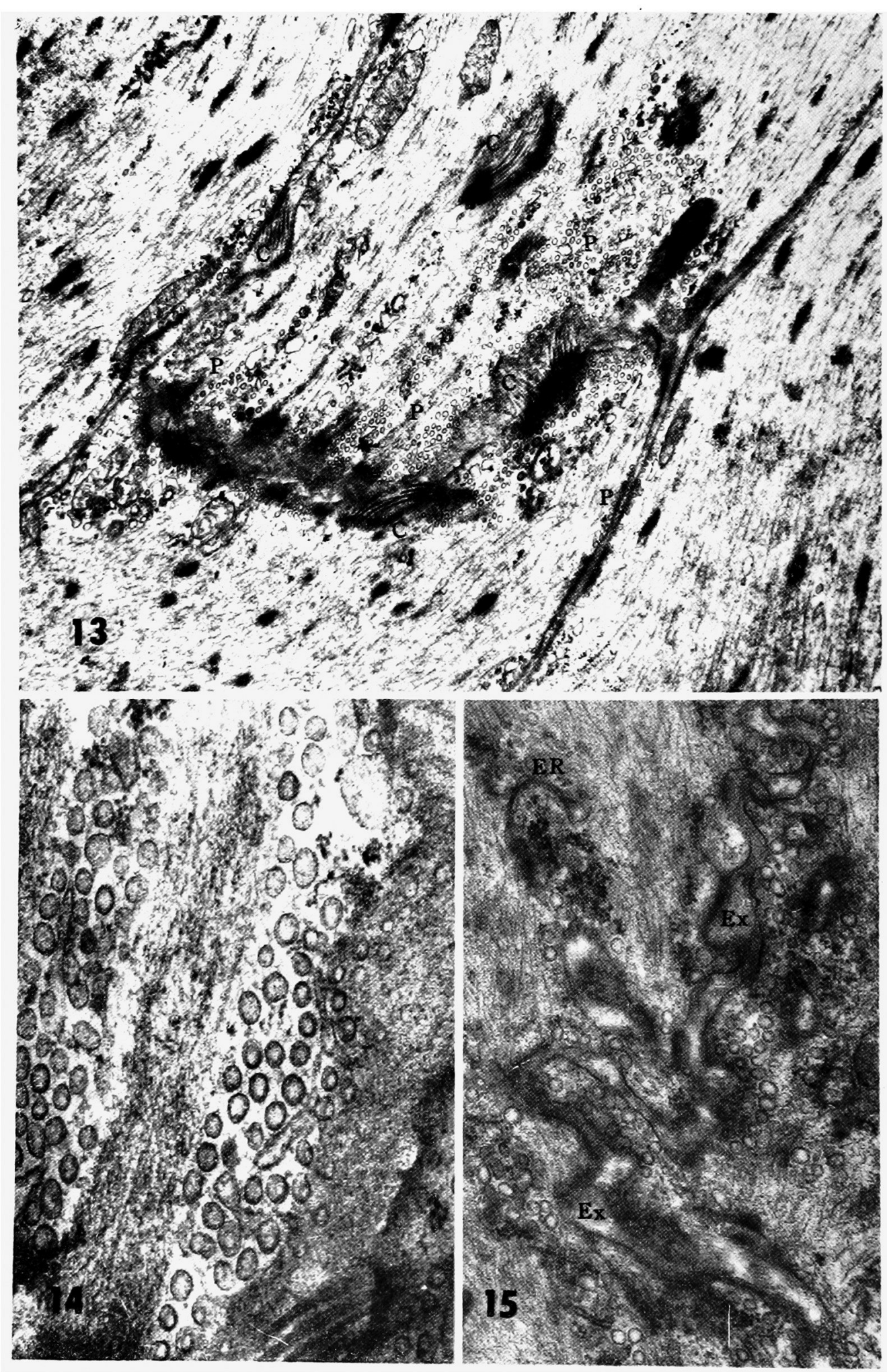



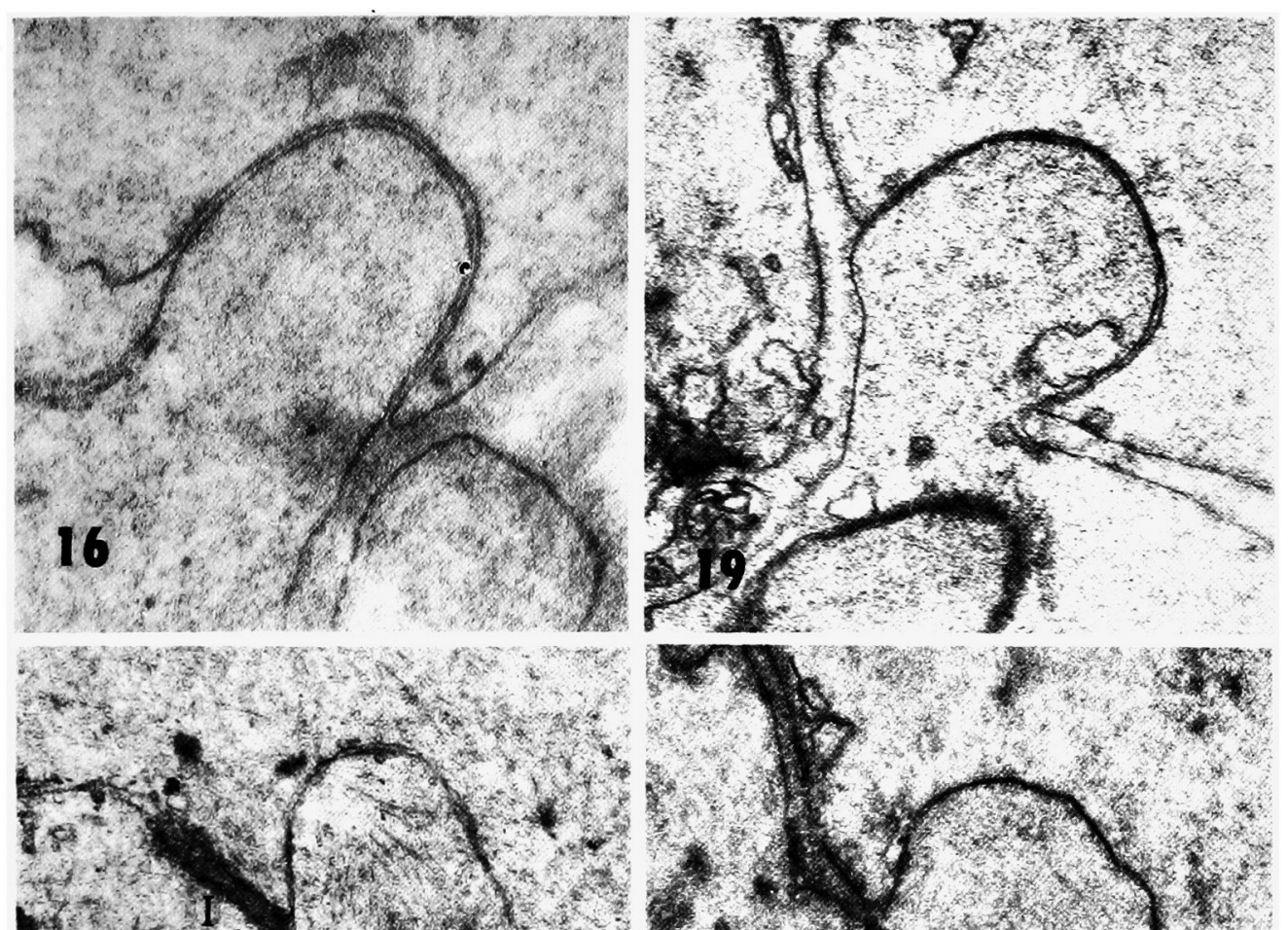

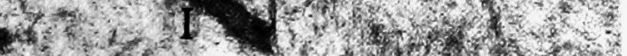

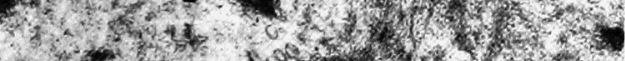

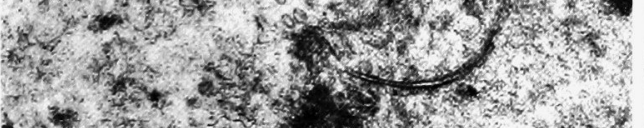

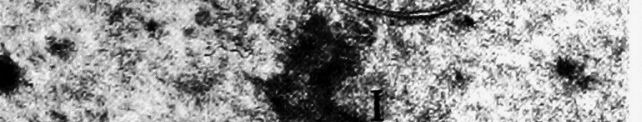

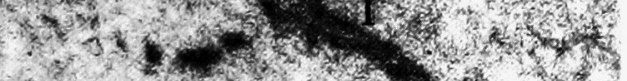
$17.2101 \div$

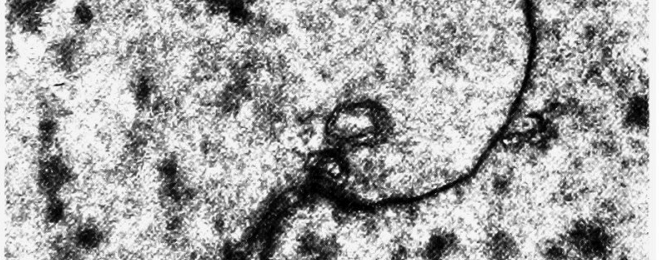

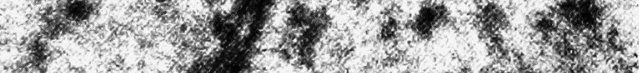

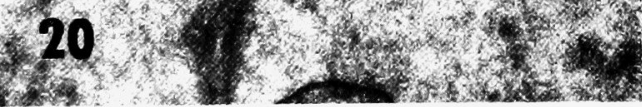

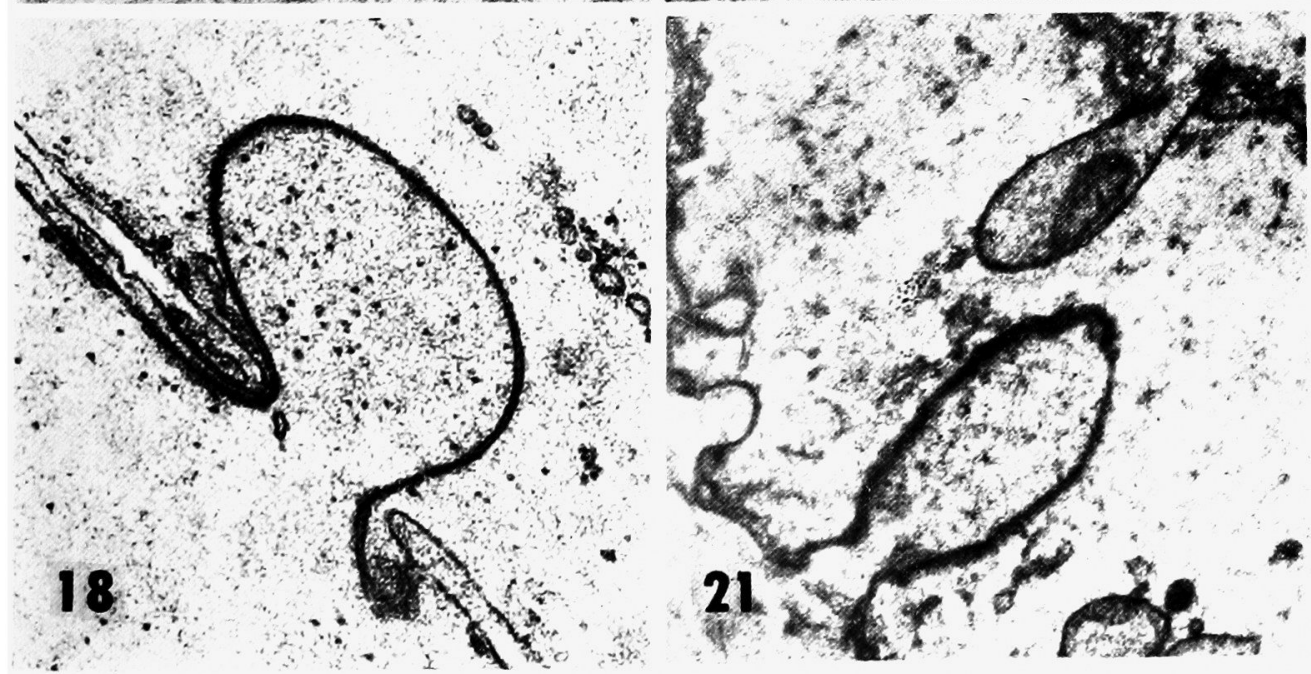

